\title{
IOT BASED FLUID MANAGEMENT AUTOMATION SYSTEM USING RASPBERRY PI AND ULTRASONIC SENSORS
}

Ayesha Urooj

Sir Syed University of Engineering and Technology. Karachi, (Pakistan). E-mail: aurooj161@yahoo.com ORCID: https://orcid.org/0000-0002-6985-3269

Sallar Khan

Sir Syed University of Engineering and Technology. Karachi, (Pakistan). E-mail: sallarkhan_92@yahoo.com ORCID: https://orcid.org/0000-0001-8988-3388

Sana Shafiq

Sir Syed University of Engineering and Technology. Karachi, (Pakistan). E-mail: sanashafiq2001@gmail.com ORCID: https://orcid.org/0000-0003-1873-7425

Bilal Ahmed

Sir Syed University of Engineering and Technology. Karachi, (Pakistan). E-mail: bilal-ahmed007@hotmail.com ORCID: https://orcid.org/0000-0002-4360-2103

Abdul Basit

Sir Syed University of Engineering and Technology. Karachi, (Pakistan). E-mail: basit.rr123@gmail.com ORCID: https://orcid.org/0000-0003-4044-8590

Shaheer Mustafa Ansari

Sir Syed University of Engineering and Technology. Karachi, (Pakistan). E-mail: shaheer1234@gmail.com ORCID: https://orcid.org/0000-0001-9470-9368

Recepción: 21/01/2020 Aceptación: 25/03/2020 Publicación: 30/04/2020

Gitación sugerida Suggested citation

Urooj, A., Khan, S., Shafiq, S., Ahmed, B., Basit, A., y Ansari, S. M. (2020). IoT based fluid management automation system using Raspberry Pi and ultrasonic sensors. 3C Tecnología. Glosas de innovación aplicadas a la pyme. Edición Especial, Abril 2020, 47-61. http://doi.org/10.17993/3ctecno.2020. specialissue 5.47-61 


\section{ABSTRACT}

Water crises is one of the most important problem of current era, as a huge amount of water wasted every year especially in residential and industrial. Improper timings and extensive electric consumption are one of the hectic issues faced by the society. We have successfully created a Kivy application for the user in which they can control the fluid wastage problem with the integration of hardware that includes (Microcontrollers, Ultrasonic sensors, Relay shield, node MCU 8266, and contactor). Through the help of our designed application, user can control: Water level status, Motor accessibility (on/off), status of water consumption, message alert facility of fluid. In future work, we focus to enhance the water model and will try to promote it to immense water plants as well as it can be adopted by agriculture sectors.

\section{KEYWORDS}

Crises Extensive, Kivy, Relay Shield, Consumption, Accessibilities, Immense. 


\section{INTRODUCTION AND RELATED WORK}

The water level administration has been a noteworthy issue so new strategies must be embraced to control the water level. Here are the expected framework works superior to the current framework. The current framework works along these lines that we make UI (User Interface) for the association of the client so the client can handle equipment through application so it will construct enthusiasm of client and furthermore manufacture cooperation as we probably are aware nowadays there is a great deal of wastage of water issue so we can attempt to make equipment and programming thusly that they control water from over streaming and it assumes a crucial job for client when they use Proposed framework: Here we will display the fundamental thought of our proposition. This proposed framework works beneath computerization and contains components like Raspberry pie, ultrasonic sensor, engine pump, transfer, driven, buzzer and LCD in which each component has its claim usefulness, but Arduino looks like the heart of the venture as all the components are interfaces with Arduino. The ultrasonic sensor plays a major part in determining the water level display within the tank. This sensor is fitted for both tanks upper and lower which is utilized for receiving flag and work concurring to the given condition and motor close at that time when they receive flag conjointly it can do tight clamp versa it can be on and works agreeing to client prerequisite. We have structured a code that at whatever point the tank is getting low the engine naturally turns over and stops when the tank spans to the client required level so the engine will consequently shut so here nobody required for controlling to engine this is the principle bit of leeway of proposed framework. Since no segment contacts the water, there is no possibility of harm to the parts while in the current framework there are water verification ultrasonic sensors which can works quick as contrast with without water confirmation sensors (Varun, Kumar, Chowdary, \& Raju, 2018). Water is one of most precious and invaluable the natural resources on our planet researches observed that the scarcity of water become constantly increasing this result will be a globally shortage of water and there will not enough water to fulfil our basic needs. This major issue provokes us design a methodology to serve water wherever and whenever it is needed our methodology not just saving water, we make it usage efficient and measurable. We take two tanks one is basement tank and another is roof tank these are generally build in any residential, industrial, and commercial sectors couple of distance sensors are fixed into 
the tanks that reads water levels and transfer signals to microcontroller that will trigger the motor pump on or off when the tanks need to be filled or controlling overflowing of water.

Through this perception we will tend to control and monitor water usage and consumption water monitoring parameters helps in saving of water. If in case they are inappropriate the model and its deployment area required audit or inspection by our team, our skilled workers and developers diagnose the different parameters such as hardware software and field area. On the other hand, hardware models (motors) are automate by android application through the cloud service that make this project smart and IoT based (Rao et al., 2018). Inserted structure is presently a day's assuming an important job in engineering configuration process for productive examination process and successful activity. Because of time unpredictability in electronic viewpoints installed structure have turned into a noticeable piece of our everyday life. So hence, with the assistance of installed structure we have monitored a venture which can quantify the water level of a capacity tank and show it on the LCD (Shetty, Wagh, \& Dudwadkar, 2018). Web of Things (IoT) can be characterized as a system of gadgets which are interconnected. It involves a lot of sensors, correspondence arrange just as programming empowered electronic gadgets that empowers end clients to procure precise information occasionally, through the correspondence channel, what's more, considers information trade among clients and the associated gadgets. This framework can be utilized to automatize the control of dams, industrial zones and so forth without human obstruction. This can likewise be utilized to accumulate data on the degree of water all through the nation. Internet of thing works faster build connection and focusses on making the sensors works more and more efficiently. Collecting the data regarding the failed sensors and provide a more reliable way to optimize and provide reliability (Siddula, Babu, \& Jain, 2018).

There have been many hydrological studies and theories have been proposed by the experts around the globe which highlight our environment changes our ecosystems mainly for the ecological role of water in our colonies, dams and powerhouses, furthermore many other researches, and experiments have also been made in recent years related to safety precautions for the usage of water and prevent it from wastage. Our study related to water resource management depends on the consumption of water by the population where water is essential to use and in what quantity? the rapid increase of population 
and an unaccountable supply and usage would be the root cause of water crises. We use ultrasonic sensors and microcontrollers on water supplies those are co-related with user mobile interface as it is observed that in the local residencies their determining the locations where schedule or unscheduled load shedding of electricity effectuate the human time and cost that will cause to uncertain water wastage and shortage, major polluting sources that contribute to water savage and its tributaries, an analysis has been made in order to evaluate the two major water storage in every house should using the water this Fluid Management Automation (F.M.A) methodology comes under the section, which is one of the most reliable management systems of the water and other fluids (Dunca, 2018).

Water may be a rare normal asset, fundamental for life and to carry out the endless larger part of economic activities. It is crucial, non-expandable by the unimportant will of man, unpredictable in its way of presenting itself in time and space, effectively defenseless and helpless of progressive employments (Durán-Sánchez, Álvarez-García, \& del Río-Rama, 2018). The fluid water management system present in the application which is used by the client and application stores previous records of water level information. We don't allow any user to get access on that, but admins have only the excess to check information of clients, but client can reset the password and entertain with application. The real water level present in the application shown on the application-based interface. Application-based interface stores the records of the water level data (Patil et al., 2017).

An IoT framework is made for this framework to test the capacities notice in the venture and it can likewise control the water stream and offer help as well, customer (Narendran, Pradeep, \& Ramesh, 2017). Systematically interest in new enhance has brought about higher water prices, however, without picking up the maximum capacity benefits through water competence (Levidow et al., 2014). The framework will mechanize the method by putting a single sensor unit within the tank that will occasionally take estimations of the water level and will control the tool naturally. This framework disposes of the try of individuals for everyday filling of the tank and checks for overflow. The issue like flood of water within the tank of intrigued, filter tank condition and tool overheating due to persistent utilization is method (Ahmadloo, Sobhanifar, \& Hosseini, 2014). 
This paper planned for advertise our venture in installing a control structure into a programmed water pump controller. One of the inspirations for this analysis was the need to carry an answer for the issue of water lack in different spots wiping out the significant offender misuse of water. A lot of water is misused and wasted. It will help the conditions and water cycle which thus guarantees that we spare water for our future (Patil \& Singh, 2014).

\section{RESEARCH METHODOLOGY}

As we know that the water is one of the most important and most essential natural resources for living beings, until it is used in an accountable manners this organized system Undertaking dependent on both equipment and programming where as shown in Figure 2 we can utilize distinctive equipment like distance sensors (Ultrasonic sensors HC-or JSN-SR04T) Microcontrollers (Node MCU, Raspberry Pi, Relay shield, Contactors) and made equipment as indicated by the prerequisites (Ahmadloo et al., 2014). Furthermore our proposed system of Fluid water management automation that work on some fluid and water level measurements its consumption utilization and its wastage controlling these all functionalities could be achieved by the use of programming and instructions to develop the user interactive interface an mobile application so any client can interact with the interface and cause their need to satisfy, some basic method and description of components are explained under.

\subsection{MICROCONTROLLERS}

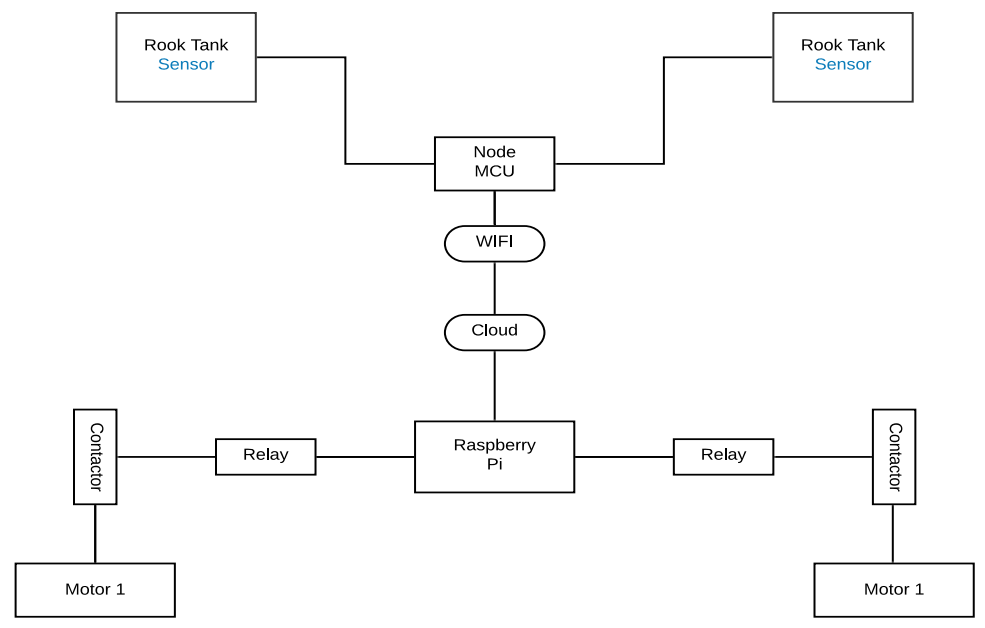

Figure 1. Structure diagram 


\subsubsection{RASPBERRY PI}

Raspberry pi as shown in Figure 2 is a credit card size board micro PC and the least expensive chip utilized by understudies. The raspberry pi is programmed to perform several operations according to our project purposes like controlling automation monitoring sequencing and displaying. Due to its size and portability, we can fix it to the desired location here we are fixing it near to motor-pump and switching board, thus our model saves time, space and cost. Raspberry pi transfers the instructions to sensors and motor pumps when the user wants, or it could automate the motors and sensors as per designed algorithm by the programmer.

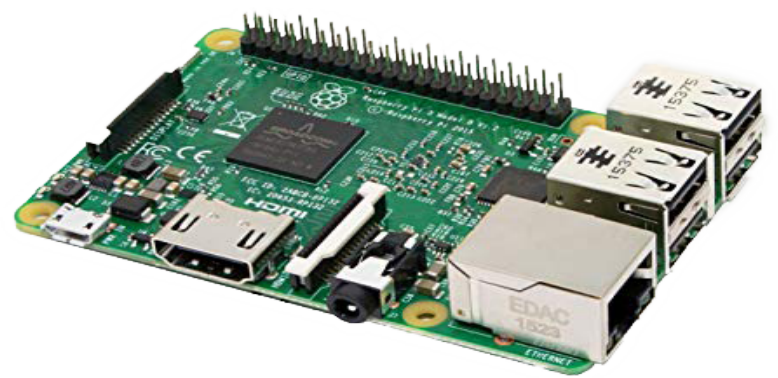

Figure 2. Raspberry Pi module 3B+.

\subsubsection{NODE MCU ESP8266}

ESP8266 is a WI-FI chip having all-inclusive TCP/IP stack and microcontroller capability as shown in Figure 3, Moreover Node MCU is an open-source platform majorly used in internet of things (IoT) based project and relevant purposes, basically ultrasonic sensors which are used in this project are not able to connect to the internet on its own because they don't have their built-in setup we use Node MCU ESP8266 to do so, we programmed with an Arduino Integrated Development Environment (IDE) and setting the connection with sensors and raspberry pie in order to perform wireless communication to an extended distance in this way both the sensors can send the readings to Raspberry Pie which performs further actions accordingly. 


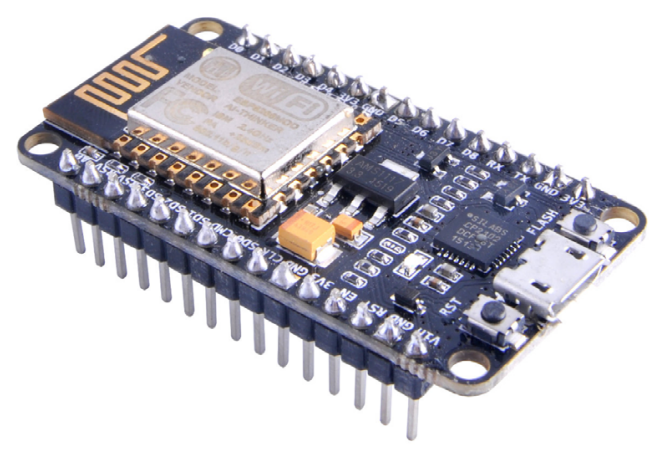

Figure 3. Node MCU 8266.

\subsection{ULTRASONIC SENSOR}

As shown in Figure 4, Ultrasonic sensor detects the object and calculates the distance of the object. The sensor head to generate an ultrasonic wave and receives the wave back after hitting the object and make some readings (Shetty, Wagh, \& Dudwadkar, 2018). Ultrasonic sensors have four pins (GND, VCG, ECHO, and TRIGGER. We have already defined levels of tanks in our system. User can check live status of water the levels of the tanks. We utilize ultrasonic sensor for both upper and lower tank so water level can distinguish for the two tanks and this work water level engine will naturally close everything should be possible since raspberry pi offers sign to ultrasonic sensor and it will close when arrived at that level (Varun et al., 2018).

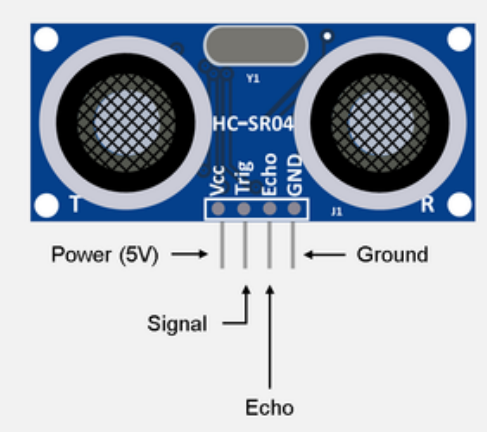

Teachwithict.com

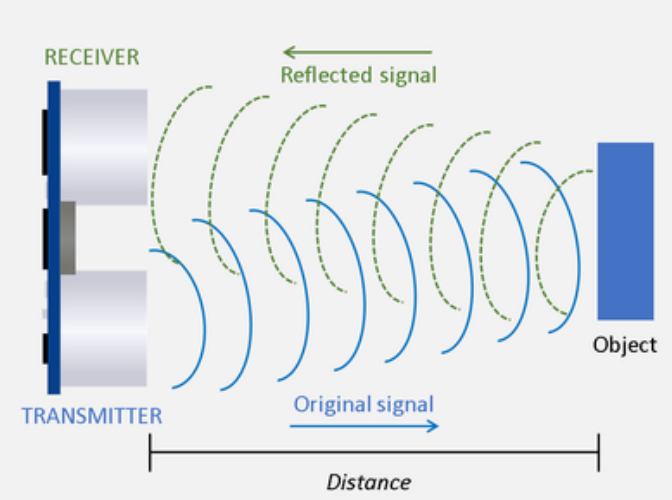

Distance

Figure 4. Receiving Signal through Ultrasonic Sensors 


\subsection{CLOUD SERVER}

Firebase included a task so we can make database effectively and store data most assuredly and by guaranteeing that all data keep private and discharge so a client can undoubtedly be enrolled with an email with no dread, Firebase would offer help and communicate client by its highlights. Here some important code for firebase as follow, as shown in below Figure 5 .

\subsubsection{CODING}

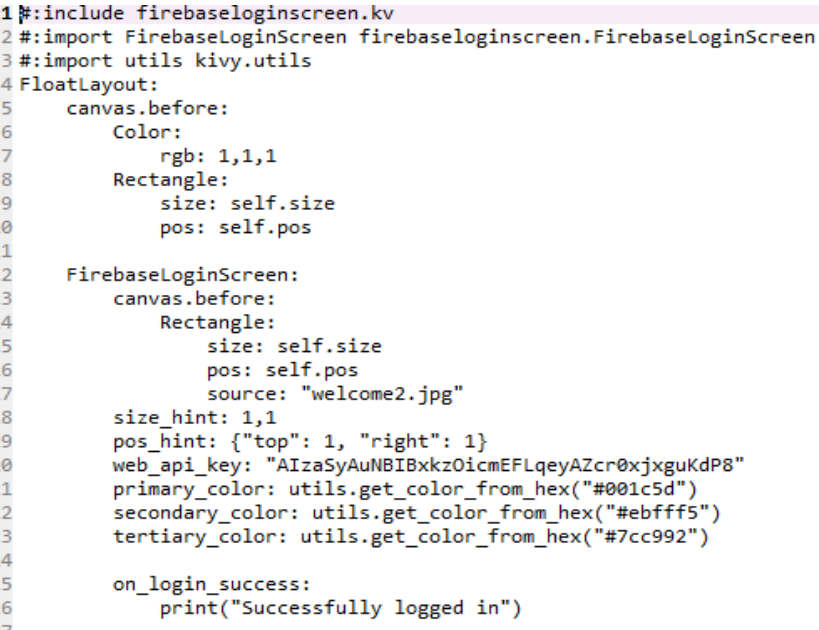

Figure 5. Firebase Coding

\subsubsection{EXPLANATION}

We can use firebase coding because it can provide support to client and also give security to admin to make client data secrete and allow client to recover security if hacked.

\section{EXPERIEMENTAL RESULTS AND DISCUSSIONS}

\subsection{USER INTERFACE (KIVY PLATFORM)}

This application is created using the software Kivy which is a python cross platform of android this all above screens are made by using the tool Spyder as we know people in society not aware with Kivy software but Kivy also use to makes interactive applications Kivy is a free and open-source Python library for creating versatile applications and another multi touch application programming with a characteristic (UI) Kivy platform also support all platform including IOS, Android and many others etc. 


\subsection{ACCESS PAGE}

Access page made so client can sign in as indicated by given ID and login secret key and login id and secret phrase spared in database. As shown in figure 6, All client should be enrolled to utilize the application and his engine data all information would save money on database and our application additionally gives the intelligent and simple interface so all sort of client can undoubtedly deal with if any client overlooked secret key so it can reset by getting email on enlisted email ID.
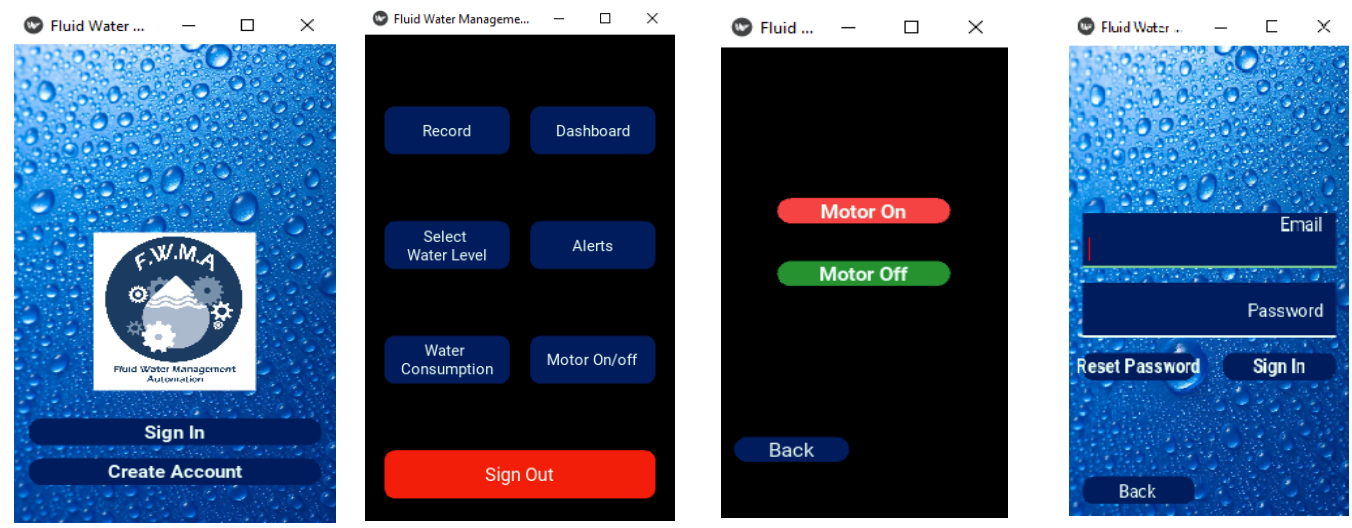

Figure 6. Mobile Application Interface

After login page, this page shows up where a client can see all capacities which incorporate into UI and client can utilize capacities like on the off chance that they, at that point need to see record or on the other hand, need to see history so a client can log in and can see the history and furthermore engage with every single given capacity.

\subsection{ALERTS}

In this capacity cautions can be sent to utilize this alarm created by an application which gets ready which stores in the database. For Ex: IF client set the engine condition 5 gallons so when arrived at that level engine will naturally be shut and produces an alert in a client mobile phone, however, there is a condition that client must sign in to utilize application capacities. 


\subsection{WORKING}

Here we can talk about the trial and dialogs which we have done and make mindful about our research paper to other individuals. The water level information is Raspberry to the microcontroller board through the WIFI (Ebere \& Francisca, 1970). The degree of water from both the tanks are gotten in a steady progression at the microcontroller. In the event that the volume is expanding, at that point, the level of water increasing and when it is going to arrive at the maximum limit of a sign is sent to the motor (Pudasaini et al., 2014). When we are implementing our system first, we measure the roof tank measurement in terms of size, volume or capacity, volume could be calculated by multiplying all three dimensions height, breadth, width. If the tank is cylindrical diameter height and pi would be multiplied, further we are scaling the tank in percentage as shown in Figure 7.

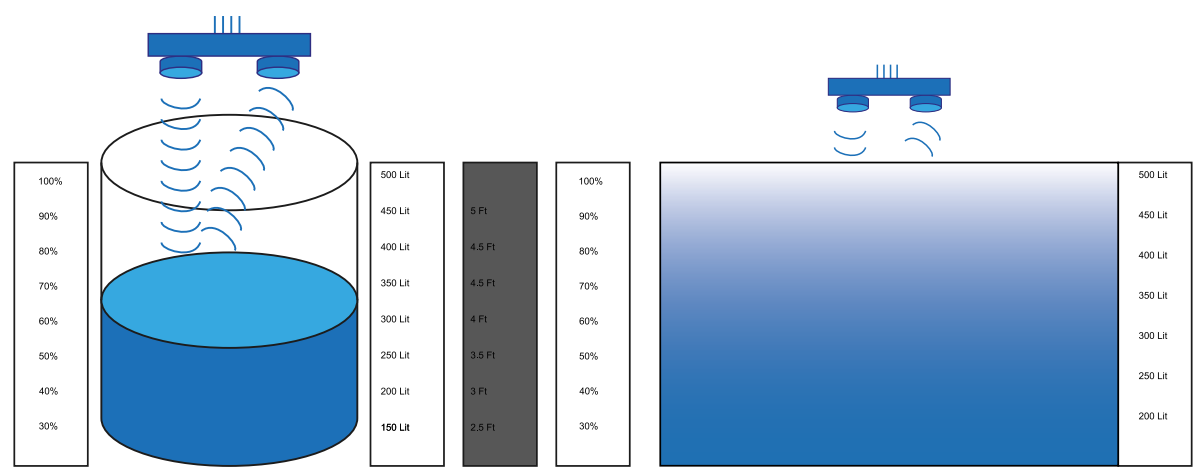

Figure 7. Cylindrical Shape Tank \& Rectangular Shape Tank

An average cylindrical and rectangular tank in residential areas are about five feet in height and have a capacity of 500 Liters of water. After measuring tanks its specification will be sent to user cloud server and microcontroller so the system will show the following attributes. The second phase of implementation or experiment user can control motors. In this utilization case outline it is simple for the client to comprehend our prerequisites plainly initially if client need to utilize our proposed framework so they should be login by making account else they can't get access of our application, when client makes get to so then one screen shows up which is essentially the UI which can be constrained by the client can check water level, water status, choice of water and furthermore they advise by our application when water arrived at that level. 


\subsubsection{USES AND APPLICATIONS}

The above administration proposed framework facilitate the procedure of water level administration. We can settle numerous related issues which we face by individuals this proposed framework works consequently as indicated by client necessity by diminishing the labor and furthermore diminished flaws.

- If there should arise an occurrence of crisis if client neglect to close the engine $p==3$ physically this application closes when water came to at given level.

- It can use in the dams for check of fluid and water.

- It can likewise help in water system where is wastage of water is more.

The proposed system is visualized and monitored by using the mobile application and some hardware's used two ultra-sonic sensors, one Raspberry pi, Micro SD card jumper wires, a breadboard, node MCU 8286, Raspberry relay shield, power supply etc. Raspberry pi is connected to the 5v Dc current through power supply. The voltage up and down are controlling with Raspberry relay shield. All the programming is set to the pins of Raspberry pi and get the result on user interface.

\section{CONCLUSION}

Human life's and world development growth are fully dependent on water. As we can see now a days water problem become common day by day so we proposed solution to overcome from wastage of water problem so user can save water in daily manner so it can help for user to avail this facility as much as they can. We made an app by which user can control water system through application in application there are different functionalities so user can entertain through different manner and save water as much as possible. Water is crucial for all of us so we can make this type of more project to overcome this problem.

\section{ACKNOWLEDMENTS}

We are deeply obliged and thankful to Mr. Ehtisham Ul Haq who guide us about technical hardware configurations and encouraged us in implementation phase. And we would also 
like to express my gratitude towards Professors, Lab assistant and to our Computer Science department, Sir Syed University of Engineering and Technology for providing us resources.

\section{REFERENCES}

Ahmadloo, E., Sobhanifar, N., \& Hosseini, F. S. (2014). Computational Fluid Dynamics Study on Water Flow in a Hollow Helical Pipe. Open fournal of Fluid Dynamics, 4(02), 133-139. https://doi.org/10.4236/ojfd.2014.42012

Dunca, A. M. (2018). Water pollution and water quality assessment of major transboundary rivers from Banat (Romania). Journal of Chemistry, 2018. https://doi. org/10.1155/2018/9073763

Durán-Sánchez, A., Álvarez-García, J., \& del Río-Rama, M. de la C. (2018). Sustainable water resources management: A bibliometric overview. Water (Switzerland), 10(9), 1-19. https://doi.org/10.3390/w10091191

Ebere, E. V., \& Francisca, O. O. (1970). Microcontroller based Automatic Water level Control System. International Fournal of Innovative Research in Computer and Communication Engineering, 2013, 1390-1396.

Rao, K., Srinija, S., Bindu, K. H., \& Kumar, D. S. (2018). IOT based water level and quality monitoring system in overhead tanks. International fournal of Engineering $\mathbb{E}$ Technology, 7(2.7), 379. https://doi.org/10.14419/ijet.v7i2.7.10747

Levidow, L., Zaccaria, D., Maia, R., Vivas, E., Todorovic, M., \& Scardigno, A. (2014). Improving water-efficient irrigation: Prospects and difficulties of innovative practices. Agricultural Water Management, 146, 84-94. https://doi.org/10.1016/j. agwat.2014.07.012

Narendran, S., Pradeep, P., \& Ramesh, M. V. (2017). An Internet of Things (IoT) based sustainable water management. GHTC 2017 - IEEE Global Humanitarian Technology Conference, Proceedings, 2017-Janua (October), 1-6. https://doi.org/10.1109/ GHTC.2017.8239320 
Patil, K. N., Tushar, K., Swaranjali, M. S., \& Shreya, M. A. (2017). IOT Based Water Level Monitoring System For Lake. International Research Journal of Engineering and Technology(IRJET), 4(2), 1425-1427. https://irjet.net/archives/V4/i2/IRJETV4I2278.pdf

Patil, Y., \& Singh, R. (2014). Smart Water Tank Management System for Residential Colonies Using Atmega128A Microcontroller. International fournal of Scientific $\mathbb{E}$ Engineering Research, 5(6), 355-357. https://www.ijser.org/researchpaper/SmartWater-Tank-Management-System-For-Residential-Colonies.pdf

Pudasaini, S., Pathak, A., Dhakal, S., \& Paudel, M. (2014). Automatic Water Level Controller with Short Messaging Service (SMS) Notification. International Journal of Scientific \& Technology Research 4(9), 1-2250. https://www.researchgate. net/publication/299825981_Automatic_Water_Level_Controller_with_Short_ Messaging_Service_SMS_Notification

Shetty, T., Wagh, P., \& Dudwadkar, A. (2018). Water level monitoring system. International Research Fournal of Engineering and Technology (IRfET), 05(08), 1712-1714. https:// www.irjet.net/archives/V5/i8/IRJET-V5I8295.pdf

Siddula, S. S., Babu, P., \& Jain, P. G. (2018). Water Level Monitoring and Management of Dams using IoT. Proceedings - 2018 3rd International Conference On Internet of Things: Smart Innovation and Usages, Io T-SIU 2018, (February), 1-5. https://doi.org/10.1109/ IoT-SIU.2018.8519843

Varun, K. S., Kumar, K. A., Chowdary, V. R., \& Raju, G. S. K. (2018). Water Level Management Using Ultrasonic Sensor (Automation). International fournal of Computer Sciences and Engineering, 6(6), 799-804. https://doi.org/10.26438/ijcse/v6i6.799804 
